5. Landon J., Lobstein T., Godfrey F., Johns P., Brookes C., Jernigan D. International codes and agreements to restrict the promotion of harmful products can hold lessons for the control of alcohol marketing. Addiction 2016; DOI: 10.1111/add.13545.

6. Mitchell A. D., Casben J. For Debate-Trade law and alcohol regulation: what role for a global alcohol marketing code? Addiction 2016; DOI:10.1111/add.13606.

\section{THE BENEFITS OF USING THE UPPS MODEL OF IMPULSIVITY RATHER THAN THE BIG FIVE WHEN ASSESSING THE RELATIONSHIP BETWEEN PERSONALITY AND PROBLEM GAMBLING}

Brunborg et al.'s recent paper [1] focuses on the relevance of personality factors associated with problem gambling (PG) in a study in which personality traits were examined along with subclinical gambling problems in a large-scale epidemiological sample. The study offers new insights into specific personality traits associated with PG, namely high neuroticism and low conscientiousness [1]. If these traits are indeed the most relevant personality dimensions linked to PG, then in our communication we would like to suggest using the UPPS model of impulsivity [2] as a more suitable framework to help us understand the relationship between personality and PG, rather than the Big Five model [3].

Based on the UPPS model [2,4], impulsivity is an umbrella construct reflected by four distinct dimensions: (i) negative urgency, defined as the tendency to act rashly while faced with intense negative emotional contexts (emotion-laden impulsivity); (ii) premeditation, defined as the tendency to take into account the consequences of an act before engaging in that act; (iii) perseverance, defined as the ability to remain focused on a task that may be boring and/or difficult; and (iv) sensation-seeking, considered as a tendency to enjoy and pursue activities that are exciting and openness to trying new experiences. In relation to the arguments developed in the current letter, it is important to emphasize that each factor has an analogue among the facets of the Big Five personality traits.

Negative urgency is related strongly to neuroticism (and not to conscientiousness, as stated erroneously by Brunborg et al. [1]). Furthermore, according to Settles et al. [5], negative urgency explains variance in externalizing behaviours beyond that accounted for by other personality factors that correlate strongly with neuroticism. Moreover, it has been shown that urgency is the impulsivity facet that distinguishes more strongly between treatment-seeking pathological gamblers and matched control participants [6]. However, in comparison to neuroticism, negative urgency is a narrower construct that has been linked to specific executive and affective mechanisms (e.g. poor pre-potent response inhibition, heightened emotion reactivity) $[7,8]$, allowing the development of more focused prevention and treatment strategies [9].

Premeditation and perseverance relate, respectively, to the 'deliberation' and 'self-discipline' facets of conscientiousness. These two UPPS components rely upon distinct underlying mechanisms [10], which are not linked identically to PG [11]. In fact, the lack of premeditation has been associated with poor decision-making abilities, which is an established hallmark of PG $[12,13]$, whereas the lack of perseverance has been linked rather to attentional processes that are not necessary altered in PG. Accordingly, it is not surprising that low premeditation (but not low perseverance) is elevated in PG. It is thus likely that screening tools able to distinguish between premeditation and perseverance are more relevant in relation to the prevention and treatment of PG than measures capturing only a broad and multi-determined construct of conscientiousness (such as the one used in Brunborg et al. [1]).

Finally, the construct of sensation-seeking (as measured by the UPPS) is probably more relevant in relation to PG than the broader construct of extraversion (measured by the Big Five and unrelated to PG in Brunborg et al. [1]). Indeed, although linked inconsistently to PG per se, a heightened level of sensation-seeking has been associated consistently with certain gambling preferences (e.g. gambling frequency, favoured types of games) [14,15], and thus constitutes relevant information when tailoring prevention efforts in gamblers (for example, in relation to specific game types).

\section{Declaration of interests}

None.

Keywords Gambling, impulsivity, personality, treatment, UPPS, urgency.

NATALE CANALE ${ }^{1}$, ALESSIO VIENO ${ }^{1}$, HENRIETTA BOWDEN-JONES ${ }^{2}$ \& JOËL BILLIEUX ${ }^{3}$

Department of Developmental and Social Psychology, University of Padova, Padova, Italy ${ }^{1}$ National Problem Gambling Clinic, London, $U^{2}$ and Laboratory for Experimental Psychopathology, Psychological Science Research Institute, Université Catholique de Louvain, Louvain-la-Neuve, Belgium ${ }^{3}$ E-mail: natale.canale@unipd.it

\section{References}

1. Brunborg G., Hanss D., Mentzoni R., Molde H., Palleson S. Problem gambling and the Five Factor model of personality: a large population-based study. Addiction 2016; 111: 1428-35. 
2. Whiteside S. P., Lynam D. R. The five factor model and impulsivity: using a structural model of personality to understand impulsivity. Pers Indiv Differ 2001; 30: 669-89.

3. Costa P. T., McCrae R. R. Revised NEO Personality Inventory (NEO-PI-R) and NEO Five-Factor Inventory (NEO-FFI) Professional Manual. Odessa, FL: Psychological Assessment Resources; 1992.

4. Cyders M. A., Smith G. T. Emotion-based dispositions to rash action: positive and negative urgency. Psychol Bull 2008; 134: 807-28.

5. Settles R. E., Fischer S., Cyders M. A., Combs J. L., Gunn R. L., Smith G. T. Negative urgency: a personality predictor of externalizing behavior characterized by neuroticism, low conscientiousness, and disagreeableness. J Abnorm Psychol 2012; 121: 160-72.

6. Michalczuk R., Bowden-Jones H., Verdejo-Garcia A., Clark L. Impulsivity and cognitive distortions in pathological gamblers attending the UK National Problem Gambling Clinic: a preliminary report. Psychol Med 2011; 41: 2625-35.

7. Wilbertz T., Deserno L., Horstmann A., Neumann J., Villringer A., Heinze H. J. et al. Response inhibition and its relation to multidimensional impulsivity. Neuroimage 2014; 103: $241-8$.

8. Lannoy S., Heeren A., Rochat L., Rossignol M., Van der Linden M., Billieux J. Is there an all-embracing construct of emotion reactivity? Adaptation and validation of the emotion reactivity scale among a French-speaking community sample. Compr Psychiatry 2014; 55: 1960-7.

9. Canale N., Vieno A., Griffiths M. D., Rubaltelli E., Santinello M. How do impulsivity traits influence problem gambling through gambling motives? The roles of perceived gambling risk/benefits. Psychol Addict Behav 2015; 29: 813-23.

10. Cyders M. A., Smith G. T. Clarifying the role of personality dispositions in risk for increased gambling behavior. Pers Indiv Differ 2008; 45: 503-8.

11. Canale N., Scacchi L., Griffiths M. D. Adolescent gambling and impulsivity: does employment during high school moderate the association? Addict Behav 2016; 60: 37-41.

12. Brevers D., Bechara A., Cleeremans A., Noël X. Iowa Gambling Task (IGT): twenty years after—gambling disorder and IGT. Front Psychol 2013; 4: 1-4.

13. Torres A., Catena A., Megías A., Maldonado A., Cándido A., Verdejo-García A. et al. Emotional and non-emotional pathways to impulsive behavior and addiction. Front Psychol 2013; 7: 1-1.

14. Smith G. T., Fischer S., Cyders M. A., Annus A. M., Spillane N. S., McCarthy D. M. On the validity and utility of discriminating among impulsivity-like traits. Assessment 2007; 14: 155-70.

15. Bonnaire C., Bungener C., Varescon I. Pathological gambling and sensation seeking - how do gamblers playing games of chance in cafés differ from those who bet on horses at the racetrack? Addict Res Theory 2006; 14: 619-29. 